\title{
Targeted therapy for human hepatic carcinoma cells using folate-functionalized polymeric micelles loaded with superparamagnetic iron oxide and sorafenib in vitro
}

\author{
This article was published in the following Dove Press journal: \\ International Journal of Nanomedicine \\ 16 April 2013 \\ Number of times this article has been viewed
}

\section{Lei Zhang' \\ Faming Gong ${ }^{2}$ \\ Fang Zhang ${ }^{3}$ \\ Jing $\mathrm{Ma}^{\prime}$ \\ Peidong Zhang' \\ Jun Shen ${ }^{3}$}

'Department of Hepatobiliary and Pancreatic Surgery, ${ }^{2}$ PCFM Laboratory of Ministry of Education, School of Chemistry and Chemical Engineering, ${ }^{3}$ Department of Radiology, Sun YatSen Memorial Hospital, Sun Yat-Sen University, Guangzhou, People's Republic of China
Correspondence: Lei Zhang

Department of Hepatobiliary and Pancreatic Surgery, Sun Yat-Sen Memorial Hospital, Sun Yat-Sen University, 107 Yanjiang Road

West, Guangzhou 5 I 0 I20,

People's Republic of China

Tel +86203407 I I69

Email zhanglei646@।26.com
Background: The purpose of this study was to evaluate the inhibitory effect of targeted folatefunctionalized micelles containing superparamagnetic iron oxide nanoparticles (SPIONs) and sorafenib on human hepatic carcinoma (HepG2) cells in vitro, and to observe the feasibility of surveillance of this targeting therapeutic effect by magnetic resonance imaging.

Methods: Sorafenib and SPIONs were loaded into polymeric micelles. The targeted nanocarrier was synthesized by functionalizing the micelles with folate. Folate-free micelles loaded with sorafenib and SPIONs were used as control (nontargeted) micelles. Uptake of the nanocarrier by cells was assessed using Prussian blue staining after 1 hour of incubation with the polymeric micelles. The inhibitory effect of the targeted micelles on HepG2 cell proliferation at various concentrations of sorafenib was assessed in vitro using the methyl thiazolyl tetrazolium (MTT) assay and apoptotic analysis using flow cytometry. Magnetic resonance imaging using a clinical $1.5 \mathrm{~T}$ scanner was performed to detect changes in the signal intensity of cells after incubation with the targeted micelles.

Results: Prussian blue staining showed significantly more intracellular SPIONs in cells incubated with the targeted micelles than those incubated with nontargeted micelles. The MTT assay showed that the average inhibitory ratio in the targeted group was significantly higher than that in the nontargeted group $(38.13 \%$ versus $22.54 \%, P=0.028)$. The mean apoptotic rate in the targeted cells, nontargeted cells, and untreated cells was $17.01 \%, 11.04 \%$, and $7.89 \%$, respectively. The apoptotic rate in the targeted cells was significantly higher than the nontargeted cells $(P=0.043)$. The T2 signal intensity on magnetic resonance imaging of cells treated with the targeted micelles decreased significantly with increasing concentrations of sorafenib in the cell culture medium, but there was no obvious decrease in signal intensity in cells treated with the nontargeted micelles.

Conclusion: Folate-functionalized polymeric micelles loaded with SPIONs and sorafenib inhibited proliferation and induced apoptosis of HepG2 cells in vitro. The inhibitory events caused by targeted micelles can be monitored using clinical magnetic resonance.

Keywords: folic acid, sorafenib, magnetic resonance imaging, superparamagnetic iron oxide nanoparticles

\section{Introduction}

Primary liver cancer is one of the most common malignant tumors, with the fifth highest incidence and third highest mortality rate of all malignancies worldwide. ${ }^{1,2}$ The incidence of liver cancer in the People's Republic of China accounts for about $55 \%$ of the global disease burden, and represents more than 60 million people 
diagnosed each year, with most having advanced disease at presentation. ${ }^{2}$ Patients with advanced liver cancer are usually not eligible for radical surgery, so medical management is the only possible treatment option. Sorafenib is the sole agent currently proven to prolong survival time significantly in patients with advanced hepatocellular carcinoma. A tyrosine kinase inhibitor, sorafenib is a targeted anticancer agent that inhibits both the RAF/MEK/ERK pathway and the receptor tyrosine kinases. ${ }^{3}$ Clinical trials have demonstrated that sorafenib can improve overall survival and limit spread of disease in patients with advanced hepatocellular carcinoma. ${ }^{4-6}$ However, many side effects, including hand-foot skin reactions, diarrhea, hypertension, fatigue, alopecia, anorexia, coronary artery spasm, and gastrointestinal bleeding decrease its tolerability, and therefore limit the therapeutic effects that can be achieved. ${ }^{7-9}$

Given the proven targeted therapeutic effects of sorafenib, patients with hepatocellular carcinoma would benefit from improvement in the efficacy and safety profile of this drug. Polymeric micelles have been used widely to improve the efficacy of drug delivery and reduce toxicity. ${ }^{10-13}$ Polymeric micelles can be concentrated in tumor tissue via the enhanced permeability and retention effect by penetrating and stranding in tumor tissue. ${ }^{14}$ Polyethylene glycol-block-poly( $\varepsilon$-caprolactone) (PEG-PCL) has been shown to have a number of attractive features and several advantages over other types of carriers, including less toxicity, biodegradability, high drug-loading efficiency, easy surface modification, and biocompatibility. ${ }^{15}$ Because folate receptors are overexpressed in tumor cells, folate is frequently conjugated with polymeric micelles for targeted drug delivery to improve the drug efficacy and safety of antitumor drugs. ${ }^{16,17}$ It is very important to be able to observe drug absorption, and magnetic resonance imaging (MRI) contrast agents, in particular, superparamagnetic iron oxide nanoparticles (SPIONs), which can be readily detected by optical microscopy or electron microscopy, are often selected as a tracer.

In this study, sorafenib as the targeted antitumor drug and SPIONs as the contrast agent were loaded in the cores of polymeric micelles. Folate was used as a targeting ligand to make the polymeric micelles active in tumor cells. The in vitro tumor cell targeting efficacy of these folatefunctionalized targeted micelles loaded with sorafenib and SPIONs was evaluated by observing uptake of the micelles in human hepatic carcinoma (HepG2) cells and by assessing their inhibitory effect on HepG2 cells which overexpress surface receptors for folic acid. The feasibility of monitoring the tumor-targeting effect in vitro by MRI was also investigated.

\section{Materials and methods Synthesis and characterization of targeted micelles}

Biodegradable polymeric micelles were synthesized by self-assembly from PEG-PCL, as described elsewehere. ${ }^{11,12}$ Sorafenib and SPIONs were then encapsulated inside the core of the micelle. In brief, $1 \mathrm{~g}$ of folic acid dissolved in $30 \mathrm{~mL}$ of anhydrous dimethylsulfoxide (Sigma, St Louis, MO, USA) was reacted overnight with $0.9 \mathrm{~g}$ of N-hydroxysuccinimide (Guangzhou Chemical Industry, Guangzhou, People's Republic of China) in the presence of $0.5 \mathrm{~g}$ of dicyclohexylcarbodiimide (Guangzhou Chemical Industry) under argon at room temperature. Next, $3 \mathrm{~mL}$ of the above activated folate solution was added to $5 \mathrm{~mL}$ of a dimethylsulfoxide solution containing $0.4 \mathrm{~g}$ of $\mathrm{NH}_{2}$-PEGPCL and $50 \mu \mathrm{L}$ of triethylamine (Guangzhou Chemical Industry) to obtain folate-PEG-PCL. Next, $10 \mathrm{mg}$ of folatePEG-PCL, $2 \mathrm{mg}$ of sorafenib, $50 \mu \mathrm{L}$ of triethylamine, and SPIONs were dissolved in a $2 \mathrm{~mL}$ solution of tetrahydrofuran and dimethylsulfoxide $(\mathrm{v} / \mathrm{v}=1)$. The dissolved mixture was added to deionized water under dropwise sonication using a UP $50 \mathrm{H}$ dismembrator (Hielscher Ultrasonics $\mathrm{GmbH}$, Teltow, Germany). This solution was then dialyzed against deionized water for 48 hours to allow formation of micelles loaded with SPIONs and sorafenib and to remove all organic solvents and free unbound sorafenib (molecular weight cutoff, 14,000 Da). Finally, the dialyzed micelle solution was filtered using a $0.22 \mu \mathrm{m}$ membrane to remove large aggregates (Figure 1). As a control, nontargeted folate-free polymeric micelles loaded with sorafenib and SPIONs were also synthesized using the same procedure.

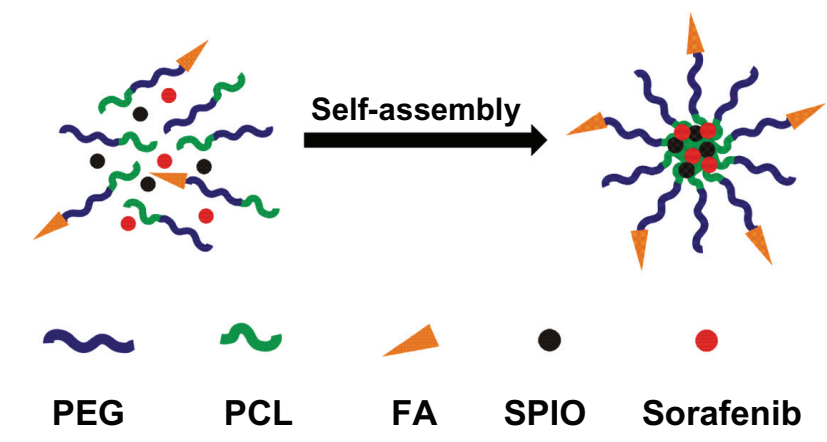

Figure I Schematic procedure for synthesis of targeted micelles.

Abbreviations: PEG, poly(ethylene glycol); PCL, poly( $\varepsilon$-caprolactone); FA, folate; SPIOs, superparamagnetic iron oxide nanoparticles. 
The amount of sorafenib loaded was quantified using an ultraviolet-visible spectrophotometer (UV-2000, Unico Scientific, Dayton, NJ, USA) as follows. In brief, the micelle solutions were first lyophilized, weighed, and redissolved in a mixture of chloroform and dimethylsulfoxide (1:1, $\mathrm{v} / \mathrm{v})$. The SPIONs were then removed from the redissolved micelles by magnetic field-guided accumulation. Because the chemical groups of sorafenib have a characteristic ultraviolet absorption peak at $260 \mathrm{~nm},{ }^{18}$ absorbance at $260 \mathrm{~nm}$ was measured to determine the sorafenib content, which was calibrated using the absorption curves for various standard concentrations of sorafenib in the same mixed solvent.

The SPION content loaded inside the polymeric micelles was determined using a polarized Zeeman atomic absorption spectrophotometer (Z-2000 series, Hitachi, Tokyo, Japan). Briefly, dried micelles were weighed, suspended in $1 \mathrm{M}$ $\mathrm{HCl}$ solution to allow polymer degradation and complete dissolution of the SPION-containing micelles. Iron concentration was determined by measurement at $248.3 \mathrm{~nm}$. A standard iron absorption curve was used for calibration. The SPION loading density was calculated as the ratio of iron oxide to the total weight of the micelles.

The size and morphology of the SPIONs and micelles were observed by transmission electron microscopy (TEM) at room temperature using a JEM-2010HR device (JEOL, Tokyo, Japan) equipped with a MegaView III camera at $200 \mathrm{kV}$. A sample of the micelle dispersion was dropped onto a carbon-coated copper grid, dried in air at room temperature, stained with an aqueous solution containing $2 \mathrm{wt} \%$ phosphotungstic acid for 30 seconds, and imaged within 24 hours.

The diameters of the micelles in aqueous solution were measured at $25^{\circ} \mathrm{C}$ using a laser light scattering system comprising a BI-200SM goniometer and a BI-9000 AT digital autocorrelator (Brookhaven Instruments Corporation, Holtsville, NY, USA). A $532 \mathrm{~nm}$ vertically polarized argon ion laser was used and scattered light was detected at $90^{\circ}$ angles by the autocorrelator.

$\mathrm{T} 2$ relaxivities for both the targeted and nontargeted micelles were detected using a 1.5 Tesla Intera clinical MRI unit (Philips, The Netherlands) with an $11 \mathrm{~cm}$ circular surface coil at room temperature. T2 relaxation data were acquired using a single-section multispin echo with the following parameters: TR, $2000 \mathrm{msec}$, stepped echo time, 20-160 msec for eight steps; echo spacing, $20 \mathrm{msec}$; field of view, $120 \times 120 \mathrm{~mm}$; acquisition matrix, $256 \times 256$; section thickness, $2 \mathrm{~mm}$; and one signal acquired. The relaxivity values $\left(r_{2}\right)$ were measured using the region of interest technique. T2 relaxivities were calculated by fitting $1 / \mathrm{T} 2$ $\left(\mathrm{s}^{-1}\right)$ versus the iron concentration $(\mathrm{mM})$.

\section{Cell cultures}

HepG2 cells overexpressing surface receptors for folic acid were purchased from the Experimental Animal Center of Sun Yat-Sen University. The cells were seeded into $25 \mathrm{~cm}$ Petri dishes at $1 \times 10^{6}$ cells per well and cultured in $4 \mathrm{~mL}$ of folate-free RPMI-1640 medium (Gibco, Grand Island, NY, USA) supplemented with $10 \%$ heat-inactivated fetal bovine serum (Gibco) in a humidified incubator $\left(5 \% \mathrm{CO}_{2}\right)$ at $37^{\circ} \mathrm{C}$. After incubation for 24 hours, a predetermined amount of micelles in phosphate-buffered solution was added into each dish to adjust the iron and sorafenib concentrations.

\section{Cellular uptake of micelles}

Uptake of micelles by the cells was detected using Prussian blue staining. In total, $5 \times 10^{5} \mathrm{HepG} 2$ cells were incubated for one hour with targeted or nontargeted micelles at sorafenib concentrations of $10,5,2.5,1.25,0.625$, and $0.3125 \mu \mathrm{mol} / \mathrm{L}$ in folate-free RPMI- 1640 medium at $37^{\circ} \mathrm{C}$. The cells were then washed with phosphate-buffered solution three times and fixed with $4 \%$ formaldehyde for 10 minutes. The fixed cells were incubated with $2 \mathrm{~mL}$ of Prussian blue solution containing $36 \%$ hydrochloric acid aqueous solution and potassium ferrocyanide at $37^{\circ} \mathrm{C}$ for 30 minutes, and then washed with phosphate-buffered solution three times. Iron staining of the cells was observed under a microscope.

As a competitive inhibition experiment, folic acid was added to the cell culture medium to compete with the targeted micelles. Briefly, HepG2 cells were cultured in medium supplemented with $1 \mathrm{mmol} / \mathrm{L}$ folic acid for 30 minutes. Targeted micelles were added at six experimental concentrations of sorafenib $(10,5,2.5,1.25$, 0.625 , and $0.3125 \mu \mathrm{mol} / \mathrm{L}$ ), and the cells were cultured for a further hour.

\section{Analysis of cytotoxicity and apoptosis}

An MTT assay was used to determine the influence of targeted and nontargeted micelles on proliferation of HepG2 cells. Cells in the exponential growth phase were harvested and seeded into 96 -well plates $\left(5 \times 10^{3}\right.$ cells/well), and cultured for approximately 24 hours. The cells were then treated for one hour with targeted or nontargeted micelles at sorafenib concentrations of 10, 5, 2.5, 1.25, 0.625, and $0.3125 \mu \mathrm{mol} / \mathrm{L}$. Next, $20 \mu \mathrm{L}$ of MTT solution $(5 \mathrm{mg} / \mathrm{mL}$ in phosphate-buffered solution) was added to each well, and the plates were incubated at $37^{\circ} \mathrm{C}$ for a further 4 hours, 
allowing viable cells to reduce the yellow MTT to dark blue formazan crystals. The medium containing MTT was then removed, and $150 \mu \mathrm{L}$ of dimethyl sulfoxide was added to each well to dissolve the formazan crystals. Absorbance at $490 \mathrm{~nm}$ was measured using a microplate reader (Wellscan MK3, Labsystems Dragon Inc, Helsinki, Finland) at room temperature. The inhibition ratio was calculated using the following equation:

Inhibition ratio $=(1-$ Absorption value of experimental group/Absorption value of control group) $\times 100 \%$.

The MTT assay was also used to determine the influence of sorafenib-free nanoparticles on proliferation of HepG2 cells in order to study the cytotoxicity of the blank micelles. The cells were treated with blank micelles at PEGPCL concentrations of $10,20,40$, and $80 \mu \mathrm{g} / \mathrm{mL}$.

Apoptotic cell death induced by the targeted and nontargeted micelles was measured by flow cytometry. For analysis of apoptosis, $5 \times 10^{5} \mathrm{HepG} 2$ cells were incubated for one hour with targeted or nontargeted micelles at sorafenib concentrations of $10,5,2.5,1.25$, and $0.625 \mu \mathrm{mol} / \mathrm{L}$. Untreated cells were used as controls. The cells were then washed with phosphate-buffered solution three times and incubated with $5 \mu \mathrm{L}$ of Annexin V-FITC and $5 \mu \mathrm{L}$ of propidium iodide for 5 minutes in the dark at room temperature, and apoptosis was then detected by flow cytometry (FACSCalibur, BD Biosciences, San Jose, CA, USA).

\section{In vitro magnetic resonance imaging}

First, $5 \times 10^{5}$ HepG2 cells were incubated for one hour with targeted or nontargeted micelles at sorafenib concentrations of $10,5,2.5,1.25$, and $0.625 \mu \mathrm{mol} / \mathrm{L}$. The cells were then suspended in a $4 \%$ gelatin solution and imaged using a 1.5 Tesla MRI scanner with an $11 \mathrm{~cm}$ circular surface coil. $\mathrm{T}_{2}$-weighted images were acquired using the following parameters: TR/TE 5000/100 msec; FOV 150 mm; matrix, $256 \times 256$; and slice thickness $1.5 \mathrm{~mm}$. The T2 signal intensities of the cells on MRI were measured using the region of interest technique.

\section{Statistical analysis}

The data were expressed as the mean \pm standard deviation. The growth inhibition and apoptosis of HepG2 cells were analyzed using the Student's $t$-test. The MRI signal intensity and the rate of signal intensity were compared using analysis of variance, and pairwise comparisons between the groups were performed using the least significant difference $t$-test. $P$ values less than 0.05 were considered to be statistically significant. All statistical tests were performed using the Statistical Package for the Social Sciences software version 16.0 (SPSS Inc, Chicago, IL, USA).

\section{Results}

\section{Synthesis and characterization of targeted micelles}

TEM images for the targeted polymeric micelles are shown in Figure 2A. SPIONs were shown to be successfully loaded into the hydrophobic core of the micelles. Dynamic light scattering showed that the mean diameter for the targeted and nontargeted micelles was $74 \pm 3 \mathrm{~nm}$ and $80 \pm 3 \mathrm{~nm}$, respectively. The iron content (wt \%) for the targeted and nontargeted micelles was $16.3 \%$ and $18.1 \%$, respectively, and the sorafenib content ( $\mathrm{wt} \%$ ) was $6.2 \%$ and $6.6 \%$. The iron concentration was $0.1 \mu \mathrm{mol} / \mathrm{L}$ and the measured $\mathrm{r}_{2}$ relaxivity was $0.326 \times 10^{6} \mathrm{M}^{-1} \mathrm{~s}^{-1}$ for the targeted micelles (Figure 2B).

\section{Uptake by cells}

Entrapment of SPIONs within the micelles enabled direct visualization of their uptake by HepG2 cells. Prussian blue staining showed obvious uptake in cells incubated with targeted micelles when the concentration of sorafenib was $10 \mu \mathrm{mol} / \mathrm{L}$ (Figure 3A). Uptake of micelles into the cells increased with increasing sorafenib concentrations. No obvious uptake of SPIONs was observed when the cells were incubated with nontargeted micelles (Figure 3B). In competitive inhibitory testing, when a high content of free folic acid ( $1 \mathrm{mmol} / \mathrm{L})$ was added to the medium, uptake of targeted micelles by the cells was significantly decreased (Figure 3C).

\section{Analysis of cytotoxicity and apoptosis}

The MTT assay showed that proliferation of cells treated with targeted micelles was significantly inhibited at all sorafenib concentrations tested. The averaged inhibition ratios for targeted and nontargeted micelles were $38.13 \%$ and $22.54 \%$, respectively. The inhibition rate was greater for cells treated with targeted micelles ( $P=0.028$, Figure 4A).

The averaged inhibition ratio for the blank micelles was $-0.6 \%,-0.3 \%, 2.4 \%$, and $3.1 \%$ when PEG-PCL concentrations were $10,20,40$, and $80 \mu \mathrm{g} / \mathrm{mL}$, respectively. The inhibition rate for cells treated with the blank micelles was not significantly different from that for cells treated with phosphate-buffered solution $(P>0.05)$. The result showed 

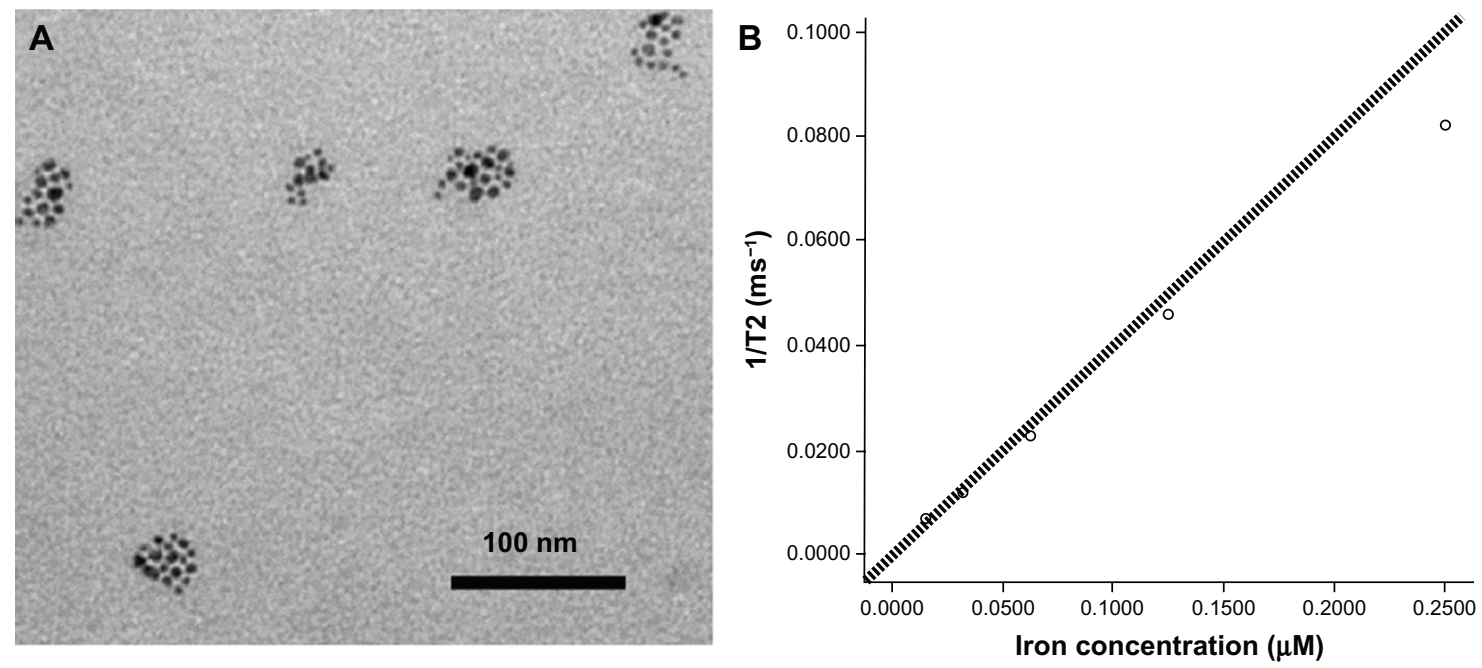

Figure 2 (A) Transmission electron microscopic images of folate-functionalized micelles containing SPIONs and sorafenib. (B) Graphs of the $r_{2}$ relaxivity of SPION-loaded micelles.

Abbreviation: SPIONs, superparamagnetic iron oxide nanoparticles.

that micelles were safe enough over a large concentration range.

The mean apoptotic rate for cells in the folate-treated group, the folate-free group, and the untreated group was $17.01 \%, 11.04 \%$, and $7.89 \%$, respectively. The apoptotic rate in the targeted group was higher than in the nontargeted group $(P=0.043$, Figure 4B).

\section{In vitro MRI}

The MRI signal intensity of cells incubated with the targeted micelles was seen to be decreased on T2-weighted imaging. This decrease in signal intensity depended on the sorafenib concentration in the cell cultures, with more obvious signal reduction found in culture medium containing a higher sorafenib concentration. In the targeted group, the differences in signal intensity and rate of signal intensity between the various sorafenib concentrations were statistically significant $(P<0.01)$. The MRI signal from cells incubated with nontargeted micelles decreased on T2-weighted imaging by about $10 \%$ when the concentration of sorafenib reached $10 \mu \mathrm{mol} / \mathrm{L}$ (Figure 5).

\section{Discussion}

Our study results show that sorafenib and SPIONs can be loaded successfully into folate-functionalized micelles. Prussian blue staining showed that more targeted micelles were taken up into cells than their nontargeted counterparts, and the competitive inhibition experiment suggested that uptake of folate-functionalized micelles containing SPIONs and sorafenib is associated with binding of the folate receptor. These micelles showed better targeting tropism to hepatic carcinoma cells in vitro and more obvious inhibition of proliferation and induction of apoptosis in HepG2 cells in vitro. Meanwhile, the cell targeting events in the micelles could be monitored using a clinical MRI scanner.
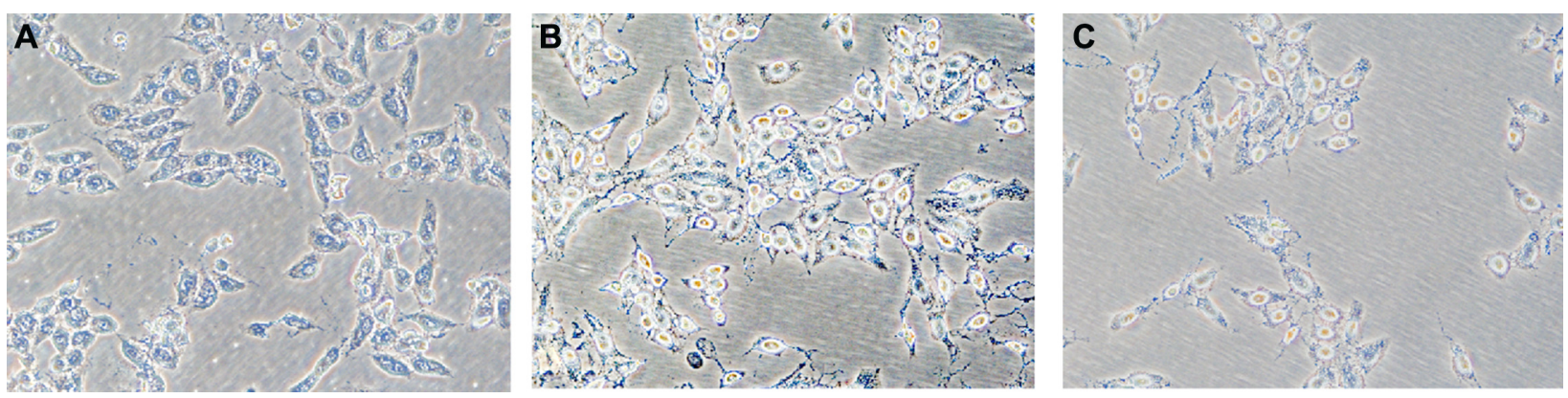

Figure 3 Prussian blue staining images $(\times 200)$ of HepG2 cells $\left(5 \times 10^{5}\right)$ after one hour of incubation with $(\mathbf{A})$ targeted and $(\mathbf{B})$ nontargeted micelles at a sorafenib concentration of $10 \mu \mathrm{mol} / \mathrm{L}$ in folate-free RPMI-1640 medium. (C) Prussian blue staining image $(\times 200)$ of HepG 2 cells $\left(5 \times 10^{5}\right)$ incubated with targeted micelles at a final sorafenib concentration of $10 \mu \mathrm{mol} / \mathrm{L}$ for one hour in folate-free RPMI- 1640 medium following 30 minutes of incubation with folic acid (I mmol/L). 

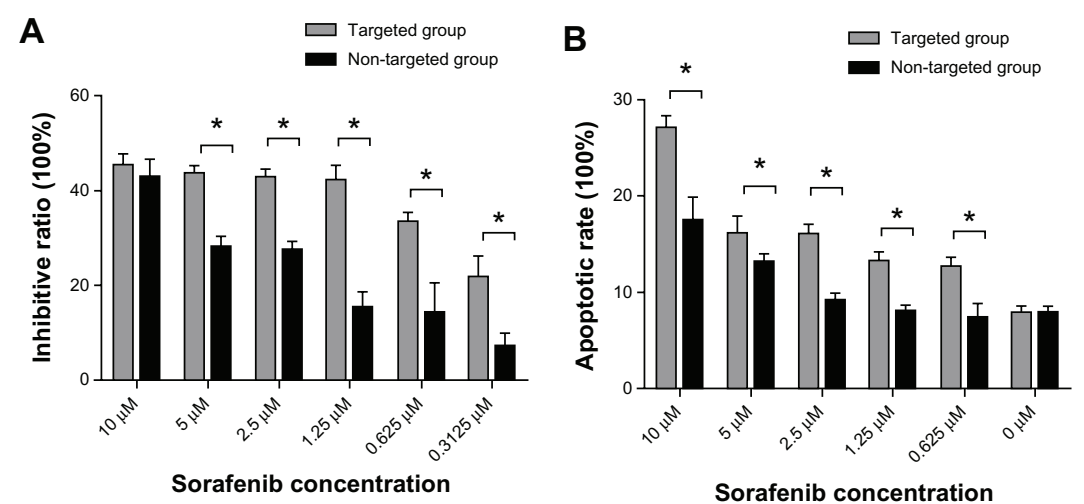

C

Sorafenib concentration
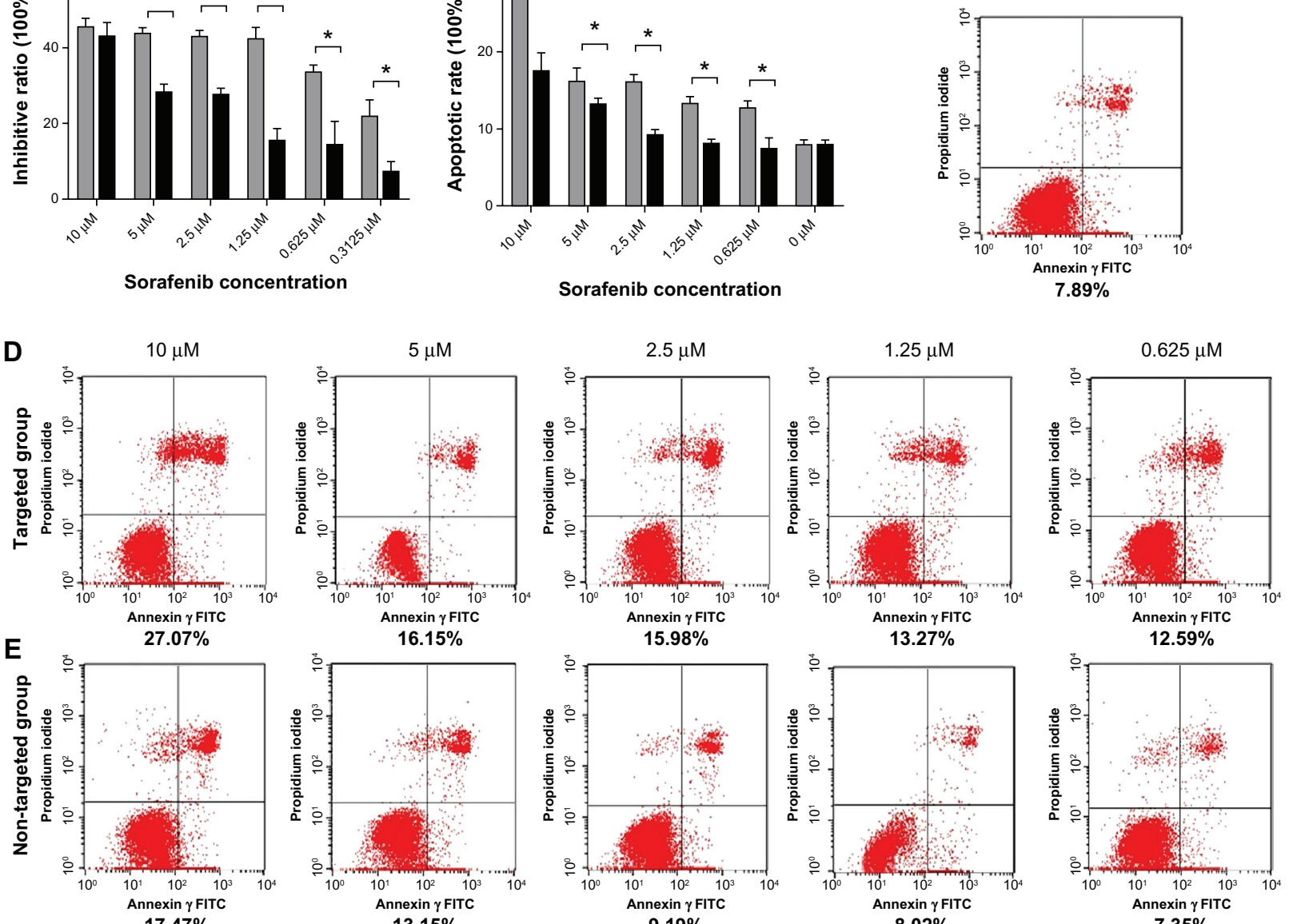

Figure 4 (A) Inhibition and (B) apoptotic rates in targeted and nontargeted micelles at different sorafenib concentrations in HepG2 cells. Data are presented as the mean \pm standard deviation, $* P<0.05$. (C) Graphs of flow cytometry for untreated cells, (D) targeted micelles, and (E) nontargeted micelles.

Doxorubicin is another anticancer drug that has been loaded into folate-targeted polymeric micelles. Folatefunctionalized micelles loaded with doxorubicin and SPIONs showed a similarly favorable drug delivery effect in hepatic carcinoma cells in vitro. ${ }^{12}$ Further, it has been demonstrated that polymeric PEG-PCL micelles are an effective carrier system for hydrophobic SPIONs and doxorubicin, and could serve as an MRI-visible targeted drug delivery system for better tumor imaging and therapy. ${ }^{19-21}$ Our experimental results show that folate-functionalized polymeric micelle systems designed as delivery vehicles can reduce the toxicity of free drugs and improve their therapeutic efficacy.

In this study, the inhibitory effect of folate-functionalized micelles loaded with doxorubicin and SPIONs on HepG2 cell proliferation in vitro as assessed by MTT assay was higher than that reported for the Bel 7402 cells reported by Hong et al (38.13\% versus $27.28 \%$, respectively). ${ }^{12}$ Moreover, the inhibitory and apoptotic effects on tumor cells increased with increasing content of sorafenib. This was in parallel with the cell uptake observed by Prussian blue staining, where a higher uptake of micelles was observed in cells incubated with a higher content of sorafenib. This simultaneous increase in uptake and inhibitory effect provides further evidence that sorafenib and SPIONs were successfully encapsulated into the core of the micelles. Because only a short incubation time (one hour) was used in our experiments, these results also support the notion that active endocytosis of the targeted micelles by tumor cells via the folate receptor was efficient in vitro. Similar to previous studies, ${ }^{12}$ we also embedded SPIONs into the cores of nanoscale micelles in the hope of obtaining a desirable T2 negative contrast effect for monitoring drug delivery by noninvasive MRI. Our experimental results indicate that better in vitro targeting tropism of multifunctional polymeric micelles to hepatic carcinoma cells could be achieved using a clinical 1.5 Tesla MRI scanner. 

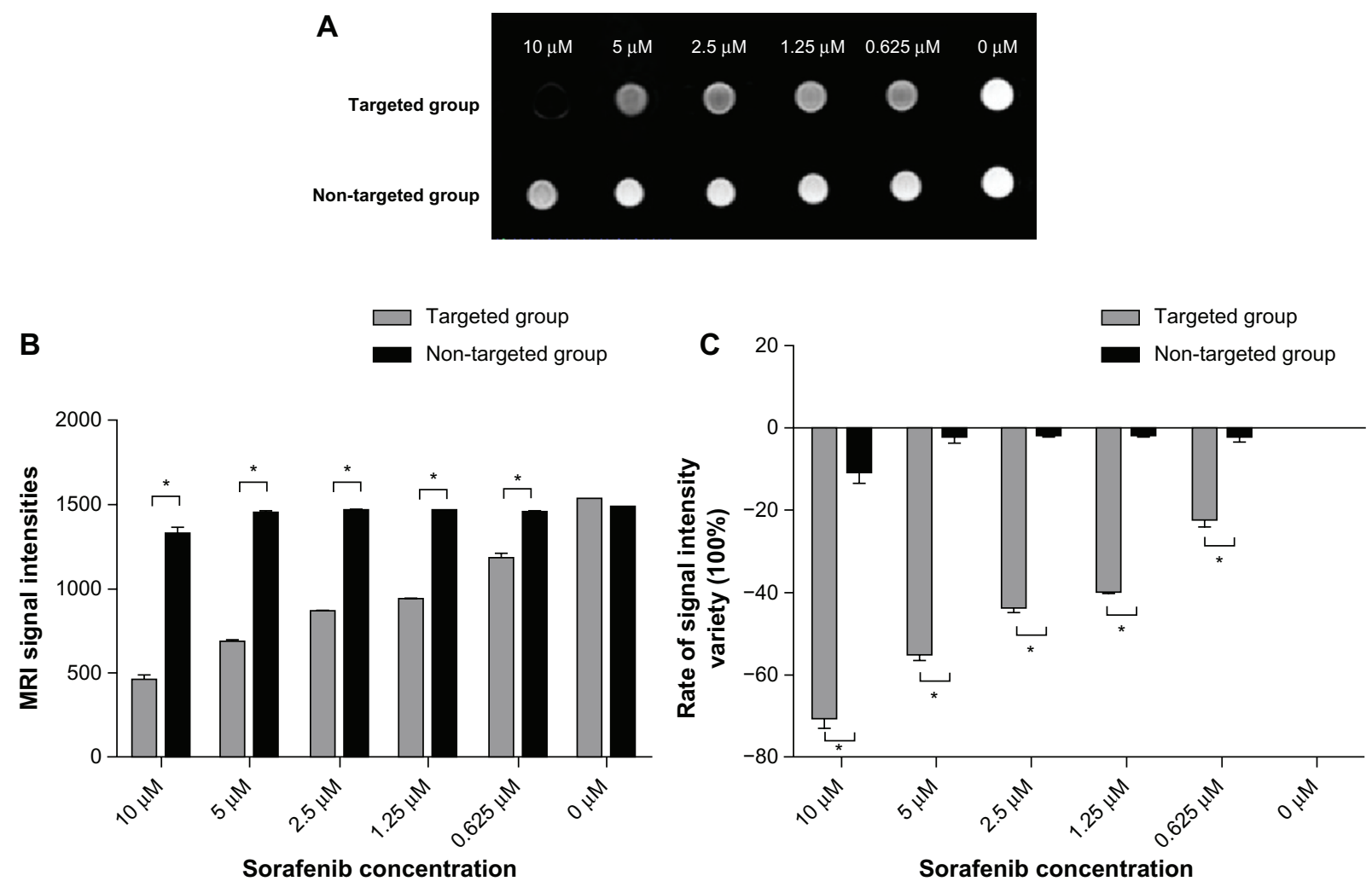

Figure 5 T2-weighted imaging of $5 \times 10^{5}$ HepG2 cells $(\mathbf{A})$ after one hour of incubation with targeted micelles (top row) and nontargeted micelles (bottom row) at final sorafenib concentrations of 10,5, 2.5, I.25, and 0.625, $\mu \mathrm{mol} / \mathrm{L}$. (B and C) Signal intensity change of targeted and nontargeted micelles at different sorafenib concentrations ( $\mu \mathrm{mol} / \mathrm{L})$ on HepG2 cells.

Note: $* P<0.05$.

Previous clinical studies have shown that drug-loaded nanoparticles may be administered orally or injected..$^{22,23}$ Nanoparticles modified by thiolated chitosan can enhance cellular uptake and cytotoxicity, and have the potential for oral administration in the treatment of cancer. ${ }^{22}$ On the other hand, the injectable form can be tailored to control drug release and thereby increase selective cell targeting, cell uptake, drug solubility, and circulation time. ${ }^{23}$ As a molecularly targeted anticancer drug, sorafenib requires oral administration at present. The targeted sorafenib-loaded micelles used in our study were designed to enable systemic delivery rather than oral delivery in the future. Considering the advantages of an injectable form of this drug, our novel sorafenib-loaded polymeric micelles would be more favorable for improvement of targeted molecular therapy in patients with advanced liver cancer.

Our study shows the potential of targeted sorafenib-loaded micelles to serve as a multifunctional nanocarrier system that combines visibility on MRI and tumor-targeted drug delivery, making these micelles a promising tumor detection probe with possible uses in imaging-guided cancer chemotherapy. However, there are some limitations to our study. First, the therapeutic efficacy and visibility of these targeted micelles were demonstrated in vitro, but their efficacy in vivo should be addressed in future research. Second, only HepG2 cells were used. HepG2 cells are a perpetual cell line that can be grown in large-scale cultivation systems, and although they are a suitable in vitro model system for the study of polarized human hepatocytes, more hepatic carcinoma cell lines with different levels of folate receptor expression need to be tested in the future to determine the efficacy of sorafenibtargeted micelles in a wide spectrum of malignant hepatic carcinoma cells.

In conclusion, our study confirms that sorafenib and SPIONs can be successfully loaded into folate-functionalized polymeric micelles. These targeted micelles can achieve better inhibition of cell growth and have a stronger apoptosisinducing effect in HepG2 cells in vitro, depending on the targeting tropism of the targeted micelles in hepatic carcinoma cells. These targeted micelles could be used as a drug delivery carrier to improve the therapeutic effect of sorafenib and reduce toxicity in the future. Because the cell targeting events of the micelles can be monitored using a clinical MRI scanner, the sorafenib-loaded targeted nanocarrier 
has high potential to be relevant to the field of translational medicine.

\section{Acknowledgment}

This work was supported by the Natural Science Foundation of Guangdong Province (S2012010009741) and the Chinese Society of Clinical Oncology (Y-B2012-001).

\section{Disclosure}

The authors report no conflicts of interest in this work.

\section{References}

1. Chan HL, Sung JJ. Hepatocellular carcinoma and hepatitis B virus. Semin Liver Dis. 2006;26:153-161.

2. Parkin DM, Bray F, Ferlay J, et al. Global cancer statistics, 2002. $C A$ Cancer J Clin. 2005;55:74-108.

3. Wilhelm SM, Carter C, Tang L, et al. BAY 43-9006 exhibits broad spectrum oral antitumor activity and targets the RAF/MEK/ERK pathway and receptor tyrosine kinases involved in tumor progession and angiogenesis. Cancer Res. 2004;64:7099-7109.

4. Abou-Alfa GK, Schwartz L, Ricci S, et al. Phase II study of sorafenib in patients with advanced hepatocellular carcinoma. J Clin Oncol. 2006;24:4293-4300.

5. Hampton T. Cancer drug trials show modest benefit: drugs target liver, gastric, head and neck cancers. JAMA. 2007;298:273-275.

6. Cheng AL, Kang YK, Chen Z, et al. Efficacy and safety of sorafenib in patients in the Asia-Pacific region with advanced hepatocellular carcinoma: a Phase III randomised, double-blind, placebo-controlled trial. Lancet Oncol. 2009;10:25-34.

7. Chu D, Lacouture ME, Fillos T, et al. Risk of hand-foot skin reaction with sorafenib: a systematic review and meta-analysis. Acta Oncol. 2008;47:176-186.

8. Arima Y, Oshima S, Noda K, et al. Sorafenib-induced acute myocardial infarction due to coronary artery spasm. $J$ Cardiol. 2009;54: 512-515.

9. Zavaglia C, Airoldi A, Mancuso A, et al. Adverse events affect sorafenib efficacy in patients with recurrent hepatocellular carcinoma after liver transplantation: experience at a single center and review of the literature. Eur J Gastroenterol Hepatol. 2013;25:180-186.
10. Parka JH, Lee S, Kim JH, et al. Polymeric nanomedicine for cancer therapy. Prog Polym Sci. 2008;33:113-137.

11. Nasongkla N, Shuai X, Ai H, et al. cRGD-functionalized polymer micelles for targeted doxorubicin delivery. Angew Chem Int Ed Engl. 2004;43:6323-6327.

12. Hong G, Yuan R, Liang B, Shen J, Yang X, Shuia X. Folatefunctionalized polymeric micelle as hepatic carcinoma-targeted, MRIultrasensitive delivery system of antitumor drugs. Biomed Microdevices. 2008; 10:693-700.

13. Lu Y, Low PS. Folate targeting of haptens to cancer cell surfaces mediates immunotherapy of syngeneic murine tumors. Cancer Immunol Immunother. 2002;51:153-162.

14. Bhattachar JJ, Vvema G, Aswal VK, et al. Tween 80-sodium deoxycholate mixed micelles: structural chacterization and application in doxorubicin delivery. J Phys Chem B. 2010;114:16414-16421.

15. Shuai X, Ai H, Nasongkla N, Kim S, Gao J. Micellar carriers based on block copolymers of poly(epsilon-caprolactone) and poly(ethylene glycol) for doxorubicin delivery. J Control Release. 2004;98: 415-426.

16. Agarwal A, Saraf S, Asthana A, et al. Ligand based dendritic systems for tumor targeting. Int J Pharm. 2008;350:3-13.

17. Yap TA, Carden CP, Kaye SB. Beyond chemotherapy: targeted therapies in ovarian cancer. Nat Rev Cancer. 2009;9:167-181.

18. Heinz WJ, Kahle K, Helle-Beyersdorf A, et al. High-performance liquid chromatographic method for the determination of sorafenib in human serum and peritoneal fluid. Cancer Chemother Pharmacol. 2011;68: 239-245.

19. Sun C, Sze R, Zhang MQ. Folic acid-PEG conjugated superparamagnetic nanoparticles for targeted cellular uptake and detection by MRI. J Biomed Mater Res A. 2006;78:550-557.

20. Xie J, Xu C, Kohler N, et al. Controlled pegylation of monodisperse $\mathrm{Fe}_{3} \mathrm{O}_{4}$ nanoparticles for reduced non-specific uptake by macrophage cells. Adv Mater. 2007;19:3163-3166.

21. Liao C, Sun Q, Liang B, Shen J, Shuai X. Targeting EGFR-overexpressing tumor cells using cetuximab immunomicelles loaded with doxorubicin and superparamagnetic iron oxide. Eur J Radiol. 2011;80:699-705.

22. Jiang L, Li X, Liu L, Zhang Q. Thiolated chitosan-modified PLAPCL-TPGS nanoparticles for oral chemotherapy of lung cancer. Nanoscale Res Lett. 2013;8:66.

23. Webster DM, Sundaram P, Byrne ME. Injectable nanomaterials for drug delivery: carriers, targeting moieties, and therapeutics. Eur J Biopharm. January 8, 2013. [Epub ahead of print.]
International Journal of Nanomedicine

\section{Publish your work in this journal}

The International Journal of Nanomedicine is an international, peerreviewed journal focusing on the application of nanotechnology in diagnostics, therapeutics, and drug delivery systems throughout the biomedical field. This journal is indexed on PubMed Central, MedLine, CAS, SciSearch $\AA$, Current Contents $₫ /$ Clinical Medicine,

\section{Dovepress}

Journal Citation Reports/Science Edition, EMBase, Scopus and the Elsevier Bibliographic databases. The manuscript management system is completely online and includes a very quick and fair peer-review system, which is all easy to use. Visit http://www.dovepress.com/ testimonials.php to read real quotes from published authors. 